\title{
ANTOLOGÍA POÉTICA DE LIVIO GÓMEZ FLORES
}

\section{Preparada por Santos Conde Lucero ${ }^{1}$}

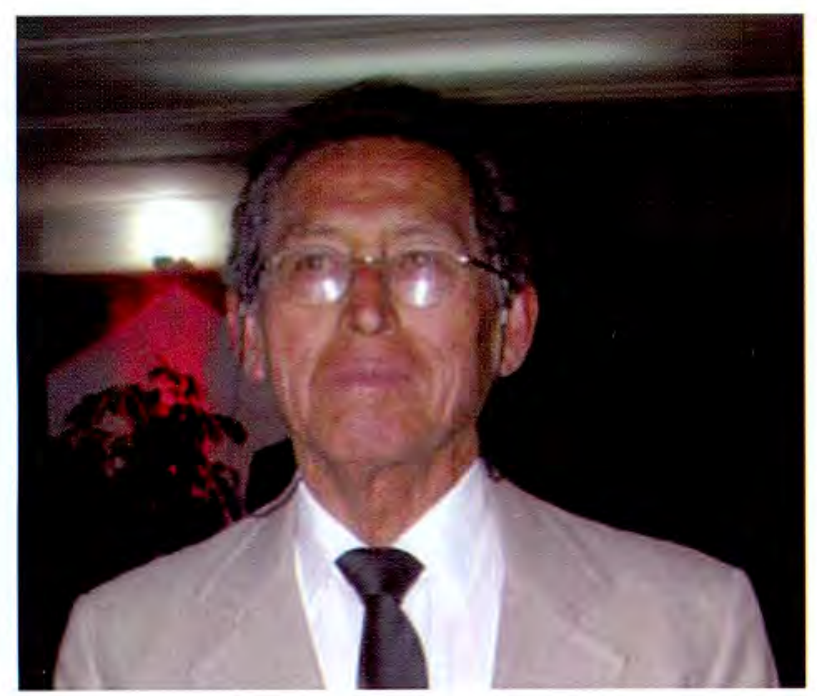

\section{DATOS BIOGRÁFICOS DEL AUTOR}

Livio Gómez Flores (Ancash, 1933 - 2010). Este recordado poeta, en vida, fue profesor de la Universidad Nacional Jorge Basadre Grohmann. Según versiones propias, sus estudios de educación media los realizó en Lima y sus estudios superiores, en la Pontificia Universidad Católica del Perú, logrando obtener el título profesional de Licenciado en Educación, con mención de Lengua y Literatura. Como artista obtuvo los siguientes galardones: Primer premio en poesía en los Juegos Florales, 1959 de la Pontificia Universidad Católica del Perú, Lima; Primer Premio en Poesía en los Juegos Florales Universitarios, 1968, organizados por la Universidad Nacional de Educación "Enrique Guzmán y Valle", Primer premio en el Concurso "El mejor Poeta Chalaco". Es autor de los siguientes libros: Infancia del olvido (1960), El día incorporado (1962), Hacia tus desvelos (1967), Fraternidades y contiendas (1968), Cómo aprovechar la lección (1976), El poema y sus alrededores (1977), Quebrantamientos (1982), Arte de puntuar (1984). También fue colaborador en revistas y diarios de circulación nacional.

Los textos selectos que se ofrece, en cierta forma, expresa, no sólo la intimidad familiar, sus dudas y sus anhelos, sino también, llama la atención, algunas reflexiones sobre el oficio del creador. Creo, particularmente, es notable su tenacidad, de modo que el ideal estético le motivó a persistir en el arte de la palabra. 


\section{ENTRE EL AMOR Y LOS DESEOS}

\section{ELEGÍA}

Ya eres una apretada quietud que hostiliza la paz de la tierra. Ya eres nada. Ya eres todo. Ya eres un recuerdo más, sitiado por mis lágrimas.

En la vida, en esto que nos dejas, en este súbito resplandor de la nada donde se abisma la congoja, fuiste una congoja más, rodeada por mi alma.

Ya el mundo ha perdido un aire tuyo, una mirada y un sollozo, y en parte se ha ido con tu muerte $y$ en parte aun alienta en mi camisa.

INFANCIA DEL OLVIDO (1969)

\section{VIENTO EN LA NOCHE}

Como una sencilla pena por mi ventana pasa el viento; también pasa la noche apretando en su pecho, en su desolado pecho, una tierna vocación de madrugadas.

\section{DECLARACIÓN JURADA}

Bajo juramento declaramos que para nosotros el poema es: la cuchara de nuestra alegría, el vaso de nuestra sed, la taza de nuestros insomnios, el espacio verbal de nuestras ansias. 


\section{MAR}

Mar,

húmeda esperanza de la tierra.

Por la edad de tus cabellos, dime;

por las arrugas de tu aliento, dime, ¿en cuál de tus páramos nocturnos, en cuál de tus profundas páginas enterrarás el rostro de todo lo que vive?

\section{ÚLTIMODESEO}

\section{A Eleodoro Vargas Vicuña}

Cuando yo me muera, enterradme en cualquier parte.

En el aire más frío, si queréis; en esa basta desolación de espadas mi cuerpo arderá como una furia.

Hay un mar que se muere de sed en sus ponientes; enterradme allí, si queréis o en la tierra que guarda un retrato de mi alma, o en el fondo de aquel poema que se calzó todos mis desvelos y ninguno le quedó bien. O en el historiado recuerdo de una batalla cavadme una tumba hecha de olvido.

Enterradme en cualquier parte, cuando yo me muera, allí donde mi silencio pueda tumbarse y beber y beber sin sosiego, ignoradas músicas entre secretas soledades. 


\section{GUÍA METAFÓRICA PARA UN JOVEN POETA}

Hay metáforas descalabradas por el rebuscamiento;

hay metáforas que son tumores verbales que agusanan la inteligibilidad del texto; hay metáforas que congestionan el tráfico de las ideas; hay metáforas que embotellan en tránsito de las sensaciones; hay metáforas desmetaforizadas por la repetición; hay metáforas que bostezan de aburrimiento porque no saben qué hacer allí donde las puso la atolondrada imaginación ; hay metáforas que son la boca jadeante del abatimiento; hay metáforas estandarizadas; hay metáforas que hacen bajar la temperatura del vértigo; hay metáforas que hacen subir la presión del entusiasmo; hay metáforas mortalmente infectadas por el patetismo; hay metáforas que desangran por una de las bocacalles del poema; hay metáforas ortopédicas, hay metáforas parasitarias, hay metáforas cancerosas.

Detéctalas tú mismo y tú mismo extírpalas. Son metáforas que pululan en aquel poema primordial que te depararon los dioses. 


\section{PROPÓSITO}

Lo que sucede en mi habitación, que es la tierra, también tendrá que suceder en la poesía que escribiré hasta que la muerte me cierre la boca.

\section{SUPERVIVENCIA}

Nades bien

o nades mal, nada todo lo que hay que nadar.

\section{LA BELLEZA}

Ella amaba las bellezas naturales, yo, las artificiales.

Ella contemplaba una flor; yo, un poema sobre esa flor.

Extinguióse la flor aquella, perdura el poema aquel.

\section{LA POESÍA CON ESFUERZO BROTA}

La palabra

con esfuerzo brilla.

Y es en el poema

donde mejor alumbra. 


\section{EPIGRAMA 2}

Tu juventud te irá dejando, te irá dejando tu hermosura hasta no ser ya más ni de los fatigados cosméticos, hasta no ser ya más ni de los espejos simiescos ni de las desmemoriadas fuentes.

Yo, el despreciado, para ti escribí este siempre joven epigrama de puntualidad incorruptible. 